\title{
DeCODE Map
}

National Cancer Institute

\section{Source}

National Cancer Institute. deCODE Map. NCI Thesaurus. Code C70942.

A high resolution genetic map based on 5136 microsatellite markers in 146 Icelandic families. 